\title{
A mitogenomic phylogeny of chitons (Mollusca: Polyplacophora)
}

\author{
Iker Irisarri ${ }^{1,2^{*}}$ (D, Juan E. Uribe ${ }^{1,3}$, Douglas J. Eernisse ${ }^{4}$ and Rafael Zardoya ${ }^{1}$
}

\begin{abstract}
Background: Polyplacophora, or chitons, have long fascinated malacologists for their distinct and rather conserved morphology and lifestyle compared to other mollusk classes. However, key aspects of their phylogeny and evolution remain unclear due to the few morphological, molecular, or combined phylogenetic analyses, particularly those addressing the relationships among the major chiton lineages.

Results: Here, we present a mitogenomic phylogeny of chitons based on 13 newly sequenced mitochondrial genomes along with eight available ones and RNAseq-derived mitochondrial sequences from four additional species. Reconstructed phylogenies largely agreed with the latest advances in chiton systematics and integrative taxonomy but we identified some conflicts that call for taxonomic revisions. Despite an overall conserved gene order in chiton mitogenomes, we described three new rearrangements that might have taxonomic utility and reconstructed the most likely scenario of gene order change in this group. Our phylogeny was time-calibrated using various fossils and relaxed molecular clocks, and the robustness of these analyses was assessed with several sensitivity analyses. The inferred ages largely agreed with previous molecular clock estimates and the fossil record, but we also noted that the ambiguities inherent to the chiton fossil record might confound molecular clock analyses.
\end{abstract}

Conclusions: In light of the reconstructed time-calibrated framework, we discuss the evolution of key morphological features and call for a continued effort towards clarifying the phylogeny and evolution of chitons.

Keywords: Bayesian, Evolution, Fossil, Maximum likelihood, Mitochondrial genome, Molecular clock, Mollusk, Mt, Timetree

\section{Background}

Chitons (Polyplacophora) are exclusively marine mollusks inhabiting a wide range of habitats from the intertidal zone to the deep sea. They generally display a conserved morphology with eight dorsal (usually overlapping) shell plates or valves, surrounded by a girdle that can bear ornamentations [1]. Chitons crawl with a ventral muscular foot that is surrounded by grooves containing rows of gills (ctenidia). Dorsal valve surfaces are covered with thousands of networked sensory organs (aesthetes). There is no head and the oral region lacks eyes or tentacles; chitons

\footnotetext{
* Correspondence: irisarri.iker@gmail.com

'Department of Biodiversity and Evolutionary Biology, Museo Nacional de Ciencias Naturales (MNCN-CSIC), c/ José Gutiérrez Abascal 2, 28006 Madrid, Spain

2Department of Organismal Biology (Systematic Biology Program),

Evolutionary Biology Centre, Uppsala University, Norbyv. 18C, 75236 Uppsala,

Sweden

Full list of author information is available at the end of the article
}

can taste the substratum with a tongue-like subradular organ, and scrape or bite food with a typical molluscan radula. The radula is ribbon-like with up to hundreds of rows of teeth, including a single pair per row coated with an extremely hard magnetite biomineral. In comparison to species-rich gastropods or bivalves, chitons are a relatively small group with about $\sim 1000$ living and 430 fossil species recognized [2, 3]. Among mollusks, living chitons are considered to be most closely related to Solenogastres (Neomeniomorpha) and Caudofoveata (Chaetodermomorpha) together forming the clade Aculifera, the sister group to Conchifera (i.e., all other living mollusks). The Aculifera hypothesis is supported by recent molecular phylogenies [4-7], paleontology [8-11], and larval musculature conditions [12]. Previously, some phylogenetic analyses proposed a closer relationship of chitons to Conchifera based on morphology (Testaria hypothesis; $[13,14]$, or to Monoplacophora based on molecular data 
(Serialia hypothesis; [15, 16]; but see [17]). The phylogenetic position of Polyplacophora holds the key to discriminating among proposed hypotheses for the mollusk phylogeny.

Chitons or chiton-like aculiferans have a long evolutionary history dating back at least to the Upper Cambrian $[3,8,18,19]$. However, most described chiton fossils are either rather recent (Late Pliocene or younger; < $4 \mathrm{Ma}$ ) or are so old (i.e., Paleozoic) that the comparison to modern chitons is difficult. Despite some exceptions [20-22], older fossils, especially from the Mesozoic, are comparatively scarce and in some cases of uncertain taxonomic assignment [3]. Identifying the phylogenetic affinity of fossils is particularly challenging in chitons given the limited utility of shell characters and the difficulty of assembling the complete set of valves (most fossils are isolated valves).

According to the latest classification by Sirenko [23], modern chitons or Neoloricata (approximately corresponding to the chiton crown-group) are arranged into two orders, Lepidopleurida and Chitonida, and the latter further divided into two suborders, Chitonina and Acanthochitonina. The relatively few molecular studies across all chitons [24] or for specific groups [25-28] have generally supported these divisions but have made only limited progress in resolving the relationships among major chiton lineages and in testing thoroughly the superfamily and family arrangements as proposed by Sirenko [23]. Members of Chitonida exhibit derived valve features compared to Lepidopleurida, such as the distal extensions of the articulamentum shell layer that anchor valves into the surrounding girdle (insertion plates); these extensions are slit with rays to permit the innervation of aesthete sensory organs spread across dorsal valve surfaces [29]. Chitonida also differ from Lepidopleurida in their lateral (not posterior) gill arrangement, ornamented egg hulls, highly modified sperm acrosomes, and fertilization processes [1,30]. Based on outgroup comparisons with other mollusks and animals, these features are considered likely derived for Chitonida whereas most key morphological characters defining Lepidopleurida have been inferred to be plesiomorphic [28, 31, 32]. Nonetheless, Lepidopleurida share at least one morphological synapomorphy: a unique sensory organ in the anterior portion of the ventral pallial groove [31]. Within Chitonida, Acanthochitonina share egg hull features and derived (abanal) gill arrangement [1,33-35], but relationships within this group remain controversial. Likewise, relationships within the more species-rich Chitonina have remained mostly unresolved, and the family Callochitonidae has alternatively been treated as either the sister lineage to all other Chitonida [30] or nested within Chitonina [23, 36].

Mitochondrial genomes (or mitogenomes) have long been used to infer phylogenetic relationships in bilaterian animals. They are relatively easy to amplify and sequence, and provide a fair number of nucleotides (or amino acids) for robust phylogeny estimation; they have a mixture of conserved and variable sites that facilitate primer design and provide information at various divergence levels; compared to nuclear genomes, the conserved set of single-copy genes makes orthology assessment straightforward and allow virtually no missing data (the same genes are present in almost all species); mitochondrial gene products are involved in housekeeping functions that are conserved across and predate bilaterians, and thus expected to be little influenced by functional convergence [37]. In addition, the almost exclusive maternal inheritance of mitogenomes results in the absence of recombination (with few exceptions, [38]), which can mislead phylogenetic inference methods [39]. In particular, the transmission of male mitochondria is prevented in Chitonida thanks to an unusual fertilization process where sperm digests a minute pore in the egg hull and injects the male nuclear DNA but blocks entry of sperm organelles [1,32]. In addition to sequence data, rare genomic changes such as gene rearrangements and duplications can provide additional characters of phylogenetic utility [40]. Bilaterian mitogenomes also present some drawbacks, including their relatively high substitution rate compared to nuclear genes $[41,42]$ that can lead to sequence saturation and long-branch attraction artifacts for deep divergences [43]. Faster evolutionary rates of rearranged genes and base compositional changes produced by gene inversions (due to mitochondrial strand biases [44];) can pose additional challenges to phylogenetic inference methods.

Despite these known analytical challenges, mitogenomes have been successfully used to reconstruct robust phylogenies in many animal groups, including mollusks (e.g., $[7,26,45,46])$. However, the thus far seven available chiton mitogenomes only represent a small glimpse of the diversity of the group and representatives of major lineages, remarkably Lepidopleurida and Callochitonidae, have been missing. This hinders not only the inference of their overall phylogeny, but also of accurate divergence times and the evolution of their mitogenome organization. The rather conserved organization of reported chiton mitogenomes $[26,47,48]$ might be beneficial for phylogenetics because it suggests limited sequence composition differences among lineages that can easily be accounted for with data partitions or mixture models.

Here, we sequenced the mitogenomes of 13 chitons across all major lineages and analyzed them together 
with available data from additional species in order to reconstruct a phylogeny of chitons. Using a relaxed molecular clock calibrated with fossil evidence, we inferred divergence times and assessed their robustness by sensitivity analyses under various calibration schemes, calibration density parameterizations, and clock models. We studied chiton mitochondrial gene orders and inferred the most likely scenario of gene order rearrangements. Finally, we discussed the evolution of key morphological features considering the chiton fossil record and our new time-calibrated phylogeny, and call for a continued effort towards clarifying the phylogeny and evolution of these fascinating mollusks.

\section{Methods}

\section{Sequencing and assembly of mitogenomes}

Information on studied species, vouchers, and sampling localities can be found in Additional file 1. Total genomic DNA was isolated using the DNeasy ${ }^{\circ}$ Blood \& Tissue Kit (QIAGEN, Carlsbad, CA, USA). The mitogenomes were amplified in a two-step procedure. First, fragments of $r r n L, c o x 1, \operatorname{cox} 3$ and $c o b$ were amplified with universal primer pairs (see Additional file 2). PCR reactions contained $2.5 \mu \mathrm{l} 10 \times \mathrm{Taq}$ Buffer advanced, $1.5 \mu \mathrm{l}$ $\mathrm{MgCl}_{2}$ (25 mM), $0.5 \mu \mathrm{ldNTP}$ mixture (10 mM each), $0.5 \mu \mathrm{l}$ of each primer ( $10 \mu \mathrm{M}$ each), $0.5 \mu \mathrm{l}$ template DNA $(10-40 \mathrm{ng} / \mu \mathrm{l}), 0.2 \mu \mathrm{l}$ 5PRIME ${ }^{\circ}$ Taq DNA polymerase (5 units/ $\mu \mathrm{l}$; 5PRIME GmbH, Hamburg, Germany), and DEPC water up to $25 \mu \mathrm{l}$. PCR cycling conditions were as follows: initial denaturation step at $94{ }^{\circ} \mathrm{C}$ for $5 \mathrm{~min}, 45$ cycles of denaturing at $94{ }^{\circ} \mathrm{C}$ for $60 \mathrm{~s}$, annealing at 44$57^{\circ} \mathrm{C}$ for $60 \mathrm{~s}$, and extending at $72^{\circ} \mathrm{C}$ for $90 \mathrm{~s}$, and a final extension at $72{ }^{\circ} \mathrm{C}$ for $5 \mathrm{~min}$. PCR products were purified by ethanol precipitation [49] and sequenced in automated DNA sequencers (ABI PRISM ${ }^{\circ}$ 3700) using the BigDye $^{\bullet}$ Terminator v3.1 cycle-sequencing kit (Applied Biosystems, Foster City, CA, USA) and PCR primers, following the manufacturer's instructions.

In a second step, the obtained sequences were used to design specific primer pairs for long PCR amplification of the remaining mitochondrial genome in 2-3 overlapping fragments (see Additional file 2). Long-PCR reactions contained $2.5 \mu \mathrm{l}$ of $10 \times$ LA Buffer II (with $\mathrm{MgCl}_{2}$ ), $4 \mu \mathrm{ldNTP}$ mixture ( $2.5 \mathrm{mM}$ each), $0.5 \mu \mathrm{l}$ of each primer $(10 \mu \mathrm{M}), 0.5 \mu \mathrm{l}$ template DNA $(10-40 \mathrm{ng} / \mu \mathrm{l})$, $0.25 \mu \mathrm{l}$ TaKaRa LA ${ }^{\circ}$ Taq DNA polymerase ( 5 units/ $\mu$ l; TaKaRa BioInc., Otsu, Japan) and DEPC water up to $25 \mu \mathrm{l}$. Long-PCR cycling conditions were as follows: initial denaturation step at $98^{\circ} \mathrm{C}$ for $30 \mathrm{~s}$; 45 cycles of denaturation at $98^{\circ} \mathrm{C}$ for $10 \mathrm{~s}$, annealing at $50-68^{\circ} \mathrm{C}$ for $30 \mathrm{~s}$, and extension at $68^{\circ} \mathrm{C}$ for $60 \mathrm{~s}$ per $\mathrm{Kb}$ of PCR product, and a final extension step at $68^{\circ} \mathrm{C}$ for $15 \mathrm{~min}$. Long-PCR products were purified by ethanol precipitation and all fragments corresponding to each mitochondrial genome were pooled together in equimolar concentrations for further steps. The mitogenome of Hanleyella oldroydi (Dall, 1919) and partial mitogenomes of Dendrochiton gothicus (Carpenter, 1864) (6764 bp) and Acanthochitona avicula (Carpenter, 1857) (2600 bp) were sequenced with a shotgun protocol using the $\mathrm{TOPO}^{\circ}$ Shotgun Subcloning Kit (Invitrogen, Carlsbad, CA, USA). Random clone libraries were constructed following the manufacturer's instructions; briefly, PCR products were sheared into $\sim 1 \mathrm{~Kb}$ fragments, which were end-repaired with $\mathrm{T} 4$ and Klenow DNA polymerases. Then, the fragments were cloned into $\mathrm{pCR}^{\circ} 4 \mathrm{Blunt}_{-\mathrm{TOPO}^{\circ}}$ vectors and transformed into TOPO10 E. coli chemically competent cells. A total of 198, 161, and 114 recombinant clones were Sangersequenced with the universal M13 forward primer for $H$. oldroyidi, $D$. gothicus and A. avicula, respectively. The remaining fragments from $D$. gothicus and $A$. avicula and all other new mitogenomes were sequenced with the Illumina technology. For each species, indexed pairend $(2 \times 100 \mathrm{bp})$ DNA libraries were constructed with either the TruSeq DNA Sample Kit (HiSeq) or the Nextera XT DNA Library Prep Kit (MiSeq) (Illumina, San Diego, CA, USA), following the manufacturer's instructions. The indexed libraries were loaded with several other indexed mitogenomes and RNAseq data from other projects into either Illumina HiSeq2000 (at Macrogen, Seoul, Korea) or Illumina MiSeq V2 500 (at Sistemas Genómicos, Valencia, Spain).

The Sanger shotgun clones were assembled using Sequencher v.5.0.1 (Gene Codes Co., Ann Arbor, MI, USA). For Illumina data, reads corresponding to different individuals were demultiplexed by the corresponding library indices and assembled using the TRUFA webserver v.0.13.3 [50]. Briefly, TRUFA performs a quality control with FastQC [51], quality-filters and trims adapters with PRINSEQ [52] and assembles contigs de novo with Trinity [53]. In a next step, Geneious ${ }^{\bullet}$ v.10.2.3 was used to extend and fuse the assembled contigs by repeatedly mapping the original filtered reads (requiring a minimum identity of $99 \%$ ), and to estimate sequencing depth. Mitogenomes were annotated by similarity to available chiton mitogenomes using Geneious and later corroborated using MITOS [37], which takes into account the inferred secondary structure of transfer RNAs (tRNAs). Ribosomal RNA (rRNA) genes were assumed to extend to the boundaries of adjacent genes [54]. In the case of Plaxiphora albida (Blainville, 1825), the final mitogenome is a composite from two partial ones that were amplified, sequenced, and assembled independently from two conspecific individuals from nearby localities (see Additional files 1 and 2) and later merged for the final alignments. In addition to newly sequenced 
mitogenomes, we also annotated two then unpublished mitogenomes available in GenBank: Acanthochitona cf. rubrolineata (Lischke, 1873) (KY827039 [55];) and Ischnochiton hakodadensis Carpenter, 1893 (KY827038 [56]; ). We further assembled transcriptomes from four available chiton RNAseq datasets: Acanthochitona crinita (Pennant, 1777) (SRR5110525; [57]), Leptochiton rugatus (Carpenter in Pilsbry, 1892) (SRR1611558 [58];), Chiton (Rhyssoplax) olivaceus Spengler, 1797 (SRR618506 [59];), and Tonicella lineata (Wood, 1815) (SRR6926331 [60];). Transcriptomes were assembled de novo using Trinity v.2.8.2 and protein-coding and rRNA genes were identified by homology search against available chiton mitogenomes using BLAST [61]. Sequencing depth, length, annotation, GenBank accession numbers, and vouchers of the new mitogenomes are available in Additional file 1 .

\section{Phylogenetic analysis}

We used the new chiton mitogenomes together with those available for Katharina tunicata (Wood, 1815) [62], Sypharochiton pelliserpentis (Quoy \& Gaimard, 1835) and Sypharochiton sinclari (Gray, 1843) [48], Cryptochiton stellerii (Middendorff, 1847), Cyanoplax cf. caverna (Eernisse, 1986), and Nuttallina californica (Reeve, 1847) [26], and Chaetopleura apiculata (Say, 1834) [47]. Solenogastres and Caudofoveata mitogenomes were used as outgroup [7, 45]. Ribosomal RNA genes and predicted amino acid sequences of proteincoding genes (using the invertebrate mitochondrial genetic code) were extracted from all mitogenomes. Individual proteins and rRNA genes were aligned with MUSCLE [63] as implemented in SeaView v.4.4.3 [64] and positions with $>80 \%$ gaps were trimmed off using BMGE v.1.12 [65]. Single gene alignments were concatenated into two matrices, one consisting exclusively of mitochondrial proteins and a second one additionally including rRNA nucleotide sequences. The amino acid composition of the protein matrix was studied using the $x^{2}$-test implemented in IQ-TREE v.1.6.10 [66] and the matched-pair tests of symmetry implemented in symtest v.2.0.37 [67].

The protein matrix was treated as a single partition. In the maximum likelihood (ML) framework, model fit was assessed in two steps: first, the best-fit replacement matrix was selected by the Bayesian Information Criterion (BIC) with ModelFinder as implemented in IQ-TREE. Then, we assessed the fit of adding empirical profile mixtures (C10 to $\mathrm{C} 60$ [68];), but this did not result in a better fit according to BIC (Additional file 3). Thus, the ML phylogeny was estimated with IQ-TREE under MtZoa $+\mathrm{F}+\mathrm{I}+\Gamma 4$ and 1000 replicates of nonparametric bootstrapping to assess branch support ('-m $\mathrm{mtZOA}+\mathrm{F}+\mathrm{I}+\mathrm{G} 4$-b 1000'). In the Bayesian inference
(BI) framework, the relative fit of the BIC-selected sitehomogeneous model $(\mathrm{MtZoa}+\Gamma 4)$ was also compared to more sophisticated mixture models (MtZoa+C60+ 4 , $\mathrm{CAT}+\Gamma 4$, and CAT-GTR $+\Gamma 4$ ) using a 10 -fold crossvalidation procedure. Cross-validation analyses clearly indicated that CAT-GTR fit the data better than MtZoa+Г4 (10 out of 10 comparisons), which was second best compared to all other models (Additional file 3). BI was performed with PhyloBayes MPI v.1.8 [69] under both CAT+GTR + Г4 ('-cat -gtr -dgam 4') and MtZoa $+\Gamma 4$ ('-mtzoa -ncat 1 -dgam 4') models. For each analysis, two independent MCMC chains were run until convergence, assessed with PhyloBayes' built-in tools (maxdiff $<0.1$ and minimum effective size $>500$; Additional file 3) and Tracer v.1.7.1 [70]. The first 25\% cycles were discarded as burnin.

The matrix of proteins and rRNA genes was treated as gene-partitioned, selecting best-fit models and partitions with BIC in ModelFinder as implemented in IQ-TREE and assuming edge-linked partitions ('- $m$ TESTMERGEONLY -spp'). The inferred best-fit models and partitions can be found in Additional file 3. Using the selected scheme (per-gene partitions), a ML tree was estimated with IQ-TREE and 1000 replicates of nonparametric bootstrapping. Two independent BI analyses were run using MrBayes v.3.2.1 [71], each with four MCMC chains for $>4$ million generations. The first $25 \%$ generations were discarded as burnin and convergence was assessed a posteriori using Tracer, and all parameters obtained ESS $>200$.

\section{Divergence time analyses}

A total of 15 calibration points were used with minimum and maximum ages derived from the fossil record and modeled as soft bounds. To account for the uncertainty and different interpretations of the fossil record, two alternative calibrations were used each for the crowngroups Polyplacophora and Chitonida (i.e., all living and extinct species descending from the most recent common ancestor of the living members) and all four possible combinations were tested in alternative calibration schemes (the remaining 13 calibration points were unaffected). Our root assumed monophyly of Polyplacophora based on previous molecular and morphological evidence $[4,8,11]$. The root (i.e., the split between crown groups Aplacophora and Polyplacophora) was calibrated at: (1a) $449.5-549 \mathrm{Ma}$ based on the Ordovician Echinochiton dufoei Pojeta Eernise, Hoare \& Henderson, 2003, which despite diverse interpretations $[8,9,11,72]$ is considered more closely related to modern chitons than to aplacophorans, or (1b) 425-549 Ma based on the Silurian Acaenoplax hayae Sutton, Briggs, Siveter \& Sigwart, 2001, considered within the total (i.e., stem plus crown) group Aplacophora $[8,9,11,73]$. The 
maximum age for the root calibrations is derived from the Cambrian deposits of the Nama group, which preserved an open marine community including the earliest animal remains but no skeletal remains of mollusks [74]. (2) Lepidopleurida was constrained at 201.3-359 Ma based on Leptochiton spp. fossils from the Upper Triassic [20, 75]. The maximum for this and all other subsequent calibrations was set at $359 \mathrm{Ma}$ as a conservative bound based on the first appearance of modern chitons with articulamentum (Neoloricata) at the beginning of the Carboniferous [3, 23]. (3) The split between Hanleyella oldroydi and Leptochiton nexus Carpenter, 1864 was constrained at 23-359 Ma based on Oligocene fossils of the former genus [23]. For Chitonida, the oldest calibration is (4a) 174-359 Ma based on Jurassic fossils such as Allochiton Fucini, 1912 and Heterochiton Fucini, 1912 [76] and Ischnochiton marloffsteinensis Fiedel \& Keupp, 1988 [22]. Because these fossils are much older than most other known Chitonida, the evidence for the typical Chitonida insertion plate slit rays is unclear, and they are described in single old studies, we used the alternative calibration (4b) 66-359 Ma based on the second oldest known Chitonida represented by the genus Chiton (see calibration 13). (5) 33.9-359 Ma for the crown-group Acanthochitonina based on Plaxiphora spp. and Acanthochitona spp. fossils [3]. (6) 33.9-359 Ma based on Acanthochitona spp. fossils [3] to date its split from Hemiarthrum setulosum Carpenter [in Dall], 1876. (7) 5.3-359 Ma based on Acanthochitona crinita fossils [3] to date its split from Acanthochitona cf. rubrolineata. (8) 3-359 Ma based on Nuttallina spp. fossils from the San Diego Formation [77] to date its split from Cyanoplax cf. caverna. (9) 15$359 \mathrm{Ma}$ the family Mopaliidae, based on the earliest known fossils of Mopalia spp. [78]. (10) 2.6-359 Ma based on Cryptochiton spp. fossils [3] to date its split from Dendrochiton gothicus, (11) 2.6-359 Ma based on Katharina tunicata fossils [3] to date its split from Tonicella lineata. (12) 33.9-359 Ma based on fossils of Chaetopleura apiculata [3] to date its split from Ischnochiton hakodadensis [63]. (13) 66-359 Ma to date the common ancestor of Chiton and Sypharochiton based on the presence of several Late Cretaceous fossils such as Chiton berryi Smith, Sohl \& Yochelson, 1968 [79], which also represents the oldest Chitonida after Allochiton, Heterochiton and Ischnochiton marloffsteinensis. (14) 33.9-359 Ma for the Acanthopleura + Tonicia clade based on fossils of the latter genus [3]. 0.01-359 Ma based on the Sypharochiton pelliserpentis fossil (=Chiton pelliserpentis; [3]) to date its split from Sypharochiton sinclairi.

Divergence time analyses relied on the Bayesian MCMCTree program within the PAML software package v.4.9e [80]. We used the protein dataset and the tree topology of BI under CAT-GTR, except that one multifurcation was resolved according to the $\mathrm{BI}$ tree under MtZoa (Additional file 4) because MCMCTree does not accept them. The root age was modeled using a uniform distribution, while all other calibrations were modeled using either (i) uniform distributions, (ii) truncatedcauchy (t-cauchy) distributions with long tails, or (iii) tcauchy distributions with short tails. Compared to uniform bounds, t-cauchy aims to model the prior divergence times using probabilistic distribution where most of the prior probability is closer to the minimum age while also retaining considerable probability mass on its tail that goes back in time. The parameterizations of $\mathrm{t}$ cauchy distributions followed Dos Reis et al. (i.e. $p=0$, $c=0.1 / 10, p_{L}=0.001$ ) [81]. Both the uncorrelated lognormal and autocorrelated relaxed clock models were tested. Calculations relied on approximate likelihood, which uses the gradient and Hessian matrix of the likelihood at the ML estimates of branch lengths $[82,83]$, which were performed with CODEML (within the PAML package) under the MtZoa $+\Gamma 4$ model. Priors on the mean (or ancestral) rate "rgene_gamma" were set to either $G(2,7.797)$ or or to $G(2,7.609)$ for schemes incorporating the root calibration $1 \mathrm{a}$ or $1 \mathrm{~b}$, corresponding to diffuse priors with mean rates of 0.2565 and 0.2628 amino acid replacements site ${ }^{-1} \mathrm{Myr}^{-1}$, respectively. Mean rates were approximated using the average rootto-tip paths in the tree of Fig. 2 and mean root ages at 499 or $487 \mathrm{Ma}$ (mean of maximum-minimum bounds) for schemes with calibrations $1 \mathrm{a}$ or $1 \mathrm{~b}$, respectively. The prior on the $\sigma^{2}$ parameter ("sigma2_gamma") was set to $G(2,2)$ indicating serious violation of the strict molecular clock. The tree prior assumed a uniform birth-death process with default parameters. The time unit was set to $100 \mathrm{Myr}$. All analyses were run for two million cycles, sampling every 100 , after the initial 20,000 cycles that were discarded as burnin. Each analysis was run twice to ensure convergence, which was checked $a$ posteriori in Tracer v.1.5. All runs showed good convergence and ESS values $>200$. In total, $48 \mathrm{MCMC}$ chains were run (four calibration schemes, three calibration distributions, two clock models, two chains per setting combination).

\section{Results}

\section{Mitochondrial genome organization}

We newly reported the gene orders for 10 complete and 3 nearly complete mitogenomes, bringing the total number of chiton mitogenomes with fully or near-fully determined gene order to 22 (Fig. 1, Additional file 1). The new mitogenomes contained the same 37 genes that are typical for bilaterians [39], and mostly matched the gene order of Chaetopleura apiculata (Chitonina) that retains the inferred ancestral gene order for chitons [47]. 

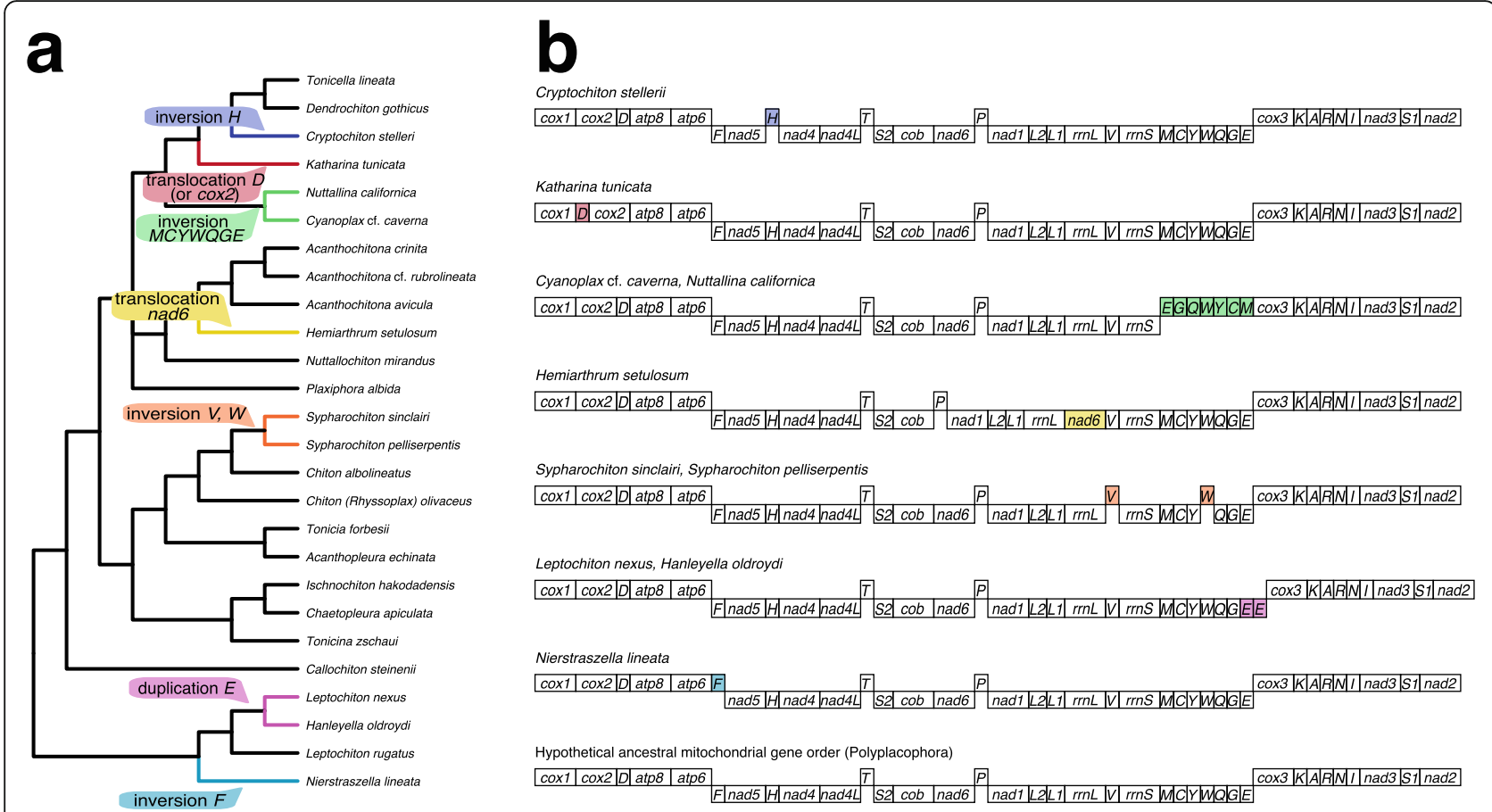

Fig. 1 Evolution of mitochondrial gene order in chitons. a Hypothesized gene rearrangements mapped onto our Bayesian phylogeny (Additional file 4). $\mathbf{b}$ Described chiton mitochondrial gene orders. The hypothesized ancestral order for chitons is based on outgroup comparison and it is also the most frequent among chitons. Genes (not to scale) are depicted as encoded either by the major (upper) and minor (lower) strand and abbreviations follow Boore [39]. Rearranged genes are colored and their inferred origin is shown onto the phylogeny a

Exceptions to this gene order were considered derived: (i) Nierstraszella lineata (Nierstrasz, 1905) (Lepidopleurida) displayed an inversion of the $\operatorname{trn} F$ gene, retaining its relative position but encoded on the major strand; (ii) Hemiarthrum setulosum (Acanthochitonina: Cryptoplacoidea) had a translocation in the nad6 gene to a new position between the $r r n L$ and $t r n V$ genes; and (iii) Hanleyella oldroydi and Leptochiton nexus (Lepidopleurida) contained two adjacent trnE genes (Fig. 1). We were unable to PCR amplify the region between the end of the $\operatorname{trn} V$ gene and the beginning of the $\operatorname{cox} 3$ gene (that includes a putative control region) for Nuttallochiton mirandus (Thiele, 1906), Callochiton steinenii (Pfeffer, 1886), and Tonicina zschaui (Pfeffer, 1886), and thus the relative gene order of the MCYWQGE tRNA cluster could not be fully determined (Additional file 1). For Acanthopleura echinata (Barnes, 1824) and Tonicia forbesii Carpenter, 1857 (Chitonina: Chitonidae), we were able to determine the gene order for this tRNA cluster but could not sequence the adjacent control region. For the three species with mitochondrial sequences derived from RNAseq data (Leptochiton rugatus, Chiton (Rhyssoplax) olivaceus, and Tonicella lineata) we explicitly avoided making claims about gene orders because the data proved insufficient to reconstruct intergenic regions with certainty.

\section{Mitogenomes helped resolving the chiton phylogeny}

Despite the ancient fossil history of chitons and the expected relatively rapid accumulation of substitutions in bilaterian mitogenomes, our inclusive analysis produced a result with robust statistical support for key relationships (Fig. 2). As rooted with aplacophorans, all our trees recovered a deep split within Polyplacophora between Lepidopleurida and Chitonida. Within Lepidopleurida, Nierstraszella (Nierstraszellidae) was the sister group to Leptochitonidae, which included Hanleyella and Leptochiton, the latter being recovered as paraphyletic. Within Chitonina, Callochiton steinenii (Callochitonidae) was the sister group of all remaining Chitonida, which comprises most extant chiton species diversity, split into Acanthochitonina and Chitonina (in this case excluding Callochitonidae).

Acanthochitonina contained three strongly-supported lineages (Plaxiphora, Nuttallochiton + Cryptoplacoidea, and Mopalioidea without Plaxiphora and Nuttallochiton) but their relative branching order was unresolved. In the ML and BI trees inferred from the combined dataset, as well as in the PhyloBayes MtZoa $+\Gamma 4$ tree inferred from the protein dataset, Plaxiphora was resolved as sister to the other two lineages with variable support (0.99 BPP; $\leq 70 \%$ BP; Fig. 2 and Additional file 4). Nuttallochiton was recovered as sister to Cryptoplacoidea, including 


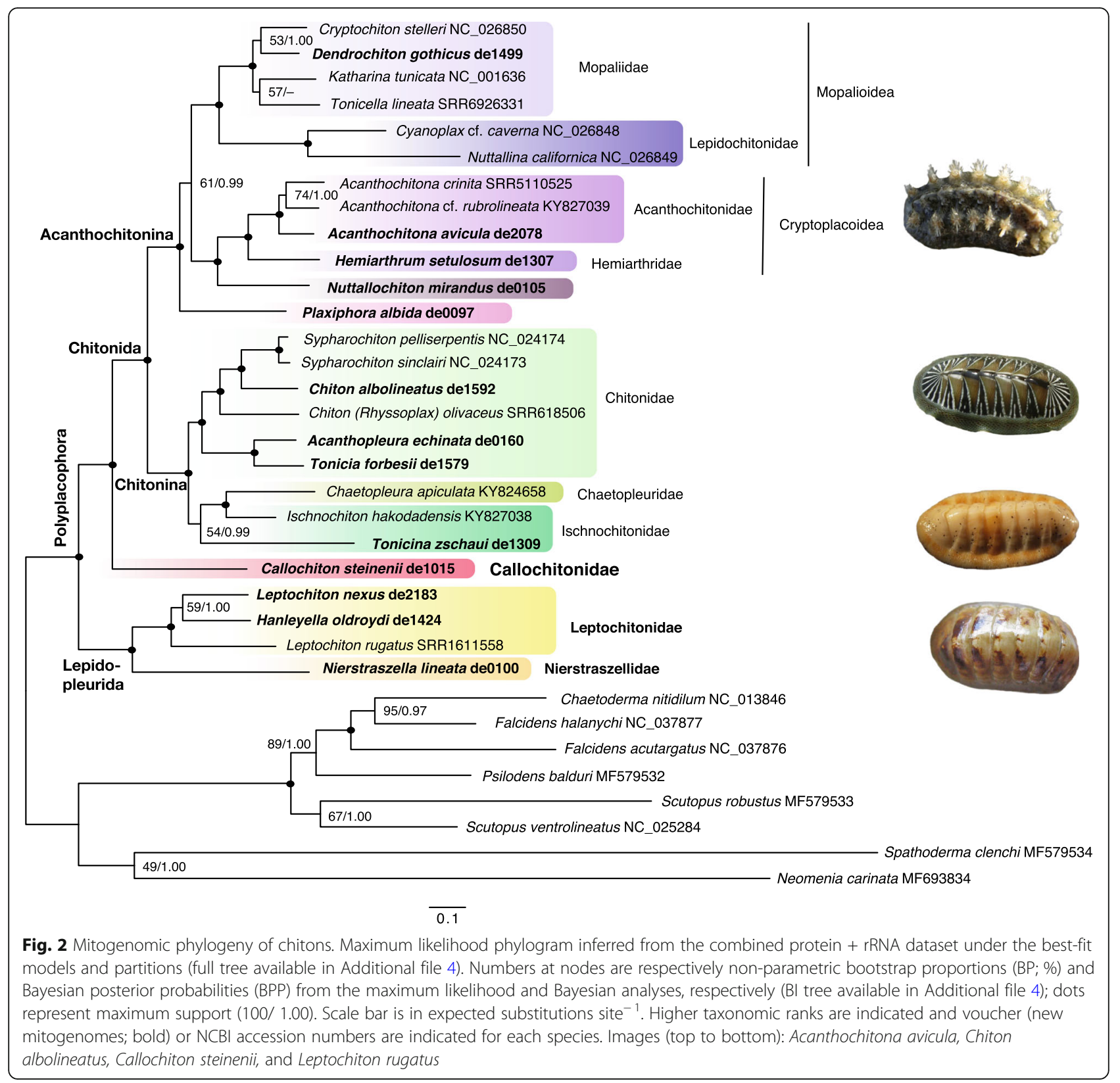

Hemiarthrum + three Acanthochitona spp., where Acanthochitona crinita and Acanthochitona cf. rubrolineata were sister taxa to the exclusion of Acanthochitona avicula, all relationships receiving strong support (Fig. 2). The monophyly of Mopaliidae sensu Kelly and Eernisse [25] was recovered with strong support, but the internal relationships were poorly resolved in both $\mathrm{BI}$ and ML trees (Fig. 2 and Additional file 4).

Within Chitonina, the trees based on combined matrices and the CAT-GTR BI tree favored Tonicina zschaui (Ischnochitonidae) as sister to Chaetopleura apiculata (Chaetopleuridae) + Ischnochiton hakodadensis (Ischnochitonidae), whereas T. zschaui was sister to all other members of Chitonina in BI and ML analyses of the protein matrix under MtZoa+F $+\mathrm{I}+\Gamma 4$ (0.99 BPP; $\leq 70 \%$ BP) (Fig. 2 and Additional file 4). Finally, Chiton albolineatus, Chiton (Rhyssoplax) olivaceus and Sypharochiton spp. were the sister group of Acanthopleura + Tonicia (Chitonidae), all relationships receiving strong statistical support (Fig. 2).

The small topological differences among the various analyses were not directly related to compositional differences among sequences. The amino acid composition of each species and results of compositional tests can be seen in Additional file 5. Compositional $\chi^{2}$-tests indicated that aplacophoran outgroups, as well as 
Leptochiton rugatus and Callochiton steinenii deviated most from the average composition. Pairwise matchedpair tests also indicated that most aplacophorans and the two chiton species mentioned above had the most deviant amino acid compositions, which resulted in nonstationary composition (evidenced by the high proportion of significant Stuart's tests; Additional file 5). None of the mentioned species were involved in conflicting relationships in our trees.

\section{Molecular dating}

Overall, the posterior ages estimated from the 24 experimental conditions (four calibration schemes, three prior fossil calibration densities, two clock models) were highly correlated ( $\rho>0.92$; Additional file 6$)$. The largest differences among experimental conditions corresponded to using different fossil calibration distributions, with short-tailed t-cauchy distribution producing younger ages than long-tailed t-cauchy and uniform distributions (the latter two showed very similar ages; $\rho>0.96$; Additional file 6). Short-tailed t-cauchy distributions represent strong priors that concentrate most of the prior probability close to fossil minima i.e., fossils ages are considered good proxies for the ages of the events being calibrated. Given the current knowledge of the chiton fossil record, such scenario might be unrealistic, and due to the large differences to other distributions, results from short-tailed $\mathrm{t}$-cauchy analyses were disregarded in the following.

The estimated ages with long-tailed t-cauchy were similar to those using uniform distributions under the uncorrelated clock model assumption, whereas they produced comparatively older estimates when rate autocorrelation was assumed (Additional files 6 and 7). Long-tailed $\mathrm{t}$-cauchy produced the widest 95\% highest probability density (HPD) intervals across all experimental conditions. The second most important factor affecting the estimated ages was the molecular clock model. Assuming rate autocorrelation resulted in overall older estimates. The ages estimated under the two clock models were most different among long-tailed t-cauchy analyses, uniform analyses being less affected and producing ages more similar to those estimated under the uncorrelated clock model (Additional files 6 and 7). Finally, the use of alternative calibration schemes had the smallest effect (Additional files 6 and 7). Given these sensitivity analyses, the ages obtained under the uncorrelated molecular clock with calibration Scheme 1 (combination of 1a and 4a calibrations; see Material and Methods) and uniform distributions were the most stable and were thus used as the main analysis of reference, highlighting differences to other analyses when relevant (results from the 24 analytical conditions are available in Additional files 6 and 7). Moreover, uniform fossil calibrations are "flat priors" that are more appropriate in the absence of strong prior information from fossils. While several studies have argued that rate autocorrelation might be a more "biologically realistic" model, we obtained more stable estimates under the uncorrelated clock. Despite the minimal effect of different calibration schemes, Scheme 1 might represent the current best attempt of understanding the chiton fossil record (Fig. 3).

Assuming uncorrelated rates and uniform calibrations from Scheme 1 (Fig. 3), the crown group Polyplacophora was dated at 338 (95\% HPD: 292-370) Ma in the Carboniferous, and the split between Callochitonidae and the remaining Chitonida at 292 (244-336) Ma in the Early Permian. The ages of Chitonida (excluding Callochiton) and Lepidopleurida were estimated at 247 (202293) $\mathrm{Ma}$ and at 247 (198-289) $\mathrm{Ma}$ in the Triassic, respectively. The earliest divergences within Acanthochitonina (156-204 Ma) and within Chitonina (160-164 Ma) occurred approximately at the same time in the Jurassic period. The ancestor of Mopalioidea was estimated to occur 156 (166-197) Ma, whereas the families Mopaliidae and (part of) Lepidochitonidae (sensu [26]) were dated at 101 (63-144) and 91 (55-131) Ma, respectively.

\section{Discussion \\ Utility of mitogenomes for resolving the chiton phylogeny}

Compared to those of gastropods or bivalves, chiton mitochondrial genomes displayed a rather conserved gene order, most species retaining the inferred ancestral gene order for mollusks [7, 47], which in turn is conserved within Bilateria [37]. In chitons, the following rearrangements could be inferred: (i) an inversion of the $t r n F$ gene in at least Nierstraszella lineata; (ii) duplication of the trnE gene prior to the common ancestor of Hanleyella and Leptochiton nexus; (iii) inversions of the trn $V$ and trn $W$ genes before the common ancestor of both Sypharochiton species; (iv) translocation of the nad6 gene in at least Hemiarthrum setulosum; (v) inversion of the MCYWQGE tRNA gene cluster prior to the common ancestor of Cyanoplax and Nuttallina; and (vi) translocation of the $\operatorname{trn} D$ gene (or the $\operatorname{cox} 2$ gene) in at least Katharina tunicata. These rearrangements are inferred as derived by outgroup comparison to mitochondrial gene orders of other mollusks and bilaterians [7, 47]. Even though the relative gene order of the MCYWQGE tRNA cluster could not be fully determined in three species (Nuttallochiton mirandus, Callochiton steinenii, and Tonicina zschaui), it is likely that they conform to the ancestral order given their phylogenetic positions and the overall stasis in gene orders. 
In agreement with the observation that tRNAs are often the most dynamic elements in mitogenomes [84], eight out of nine rearrangements involved exclusively tRNA genes. The tandem duplication and random loss model [85] is the most commonly invoked mechanism to explain gene rearrangements in mitogenomes [86]. This model could explain the transposition of the nad6 gene in Hemiarthrum, the transposition of the trnD gene in Katharina, and the duplication of the $\operatorname{trn} E$ gene in Leptochiton nexus and Henleyella. In the latter case, the two trnE genes occurred in tandem and before a noncoding region that has been proposed to contain origins of replication and transcription similarly to the control region of chordates $[87,88]$, which has been shown to be a hotspot for gene rearrangement $[86,89]$. Alternative mechanisms need to be invoked to explain the tRNA gene inversions in Cyanoplax, Nuttallina, Cryptochiton, and Sypharochiton spp., such as illegitimate recombination via minicircle [90]. Note that illegitimate recombination could also explain all the above-mentioned transpositions and duplications. The presence of any rare gene rearrangements in mitogenomes could each serve as an additional phylogenetic marker [40] that, for instance, could help clarifying the systematics within Acanthochitonina (tRNA gene rearrangements in Nuttallina, Cyanoplax and Katharina; [26]) or within Leptochitonidae (screening species for the duplication of the trnE gene found in Hanleyella and Leptochiton nexus).

Mitochondrial gene rearrangements have often been associated with increased evolutionary rates and compositional strand biases among species [37], which could confound phylogenetic inference methods. The fact that all protein-coding and rRNA genes are consistently encoded by the same strands in all sequenced chitons might have reduced the chance for rate and compositional heterogeneities among lineages. Less rearranged, slower evolving mitogenomes have been shown to produce more accurate phylogenies [46]. Despite the presence of non-stationary amino acid composition in our data (see Results), our phylogenetic analyses recovered fairly robust and congruent tree topologies, regardless of the applied models and inference methods, with only four unsettled branches left (Fig. 2, Additional file 4). All four instances are associated with short internal branches indicating potential radiation events, and these generally correspond to known taxonomic disagreements among available classification systems. Overall, mitogenomics stands out as a promising tool to clarifying the phylogeny of chitons. New chiton mitogenomes from yet unsampled lineages will likely produce robust phylogenies that resolve remaining controversies, reveal new ones, and ultimately improve our understanding of the chiton phylogeny. In addition, a phylogenomic exploration of diverse nuclear gene regions is expected to significantly contribute to this goal by providing an independent line of evidence to confirm or refute the mitogenomic phylogeny. Cost-effective high-throughput sequencing techniques such as transcriptomics and hybrid enrichment will permit broader taxon sampling and the high resolving power of (nuclear) phylogenomics, together with adequately accounting for systematic biases, will help resolve particularly difficult branching patterns, as demonstrated in other animal groups $[4,91]$.

\section{Chiton systematics, classification, and evolution}

The deep structure of the chiton tree approximately corresponds with the currently recognized major lineages: a deep split separates the order Lepidopleurida from Callochiton and all other remaining Chitonida, the latter being divided into Chitonina and Acanthochitonina (Fig. 2). The position of Callochitonidae (represented here by Callochiton) has been a major point of controversy in chiton systematics [23, 27, 30, 92]. Our recovery of Callochiton as sister group to all other Chitonida agrees with several previous molecular studies [26, 93] but contradicts others. In Sigwart et al. [27] Callochiton was sister to Acanthochitonina, but this might be due to a limited representation of Chitonina and Lepidopleurida in their dataset. In Okusu et al. [24], Callochiton was sister to Lepidopleurida, a result that conflicts with morphological evidence and could derive from a combination of limited taxon and gene sampling (e.g. no rrnL data was available for Callochiton) and rooting problems. The position of Callochiton as sister to all other Chitonida is supported by its mostly smooth egg hull, symmetrically arranged mitochondria into an otherwise Chitonida-like sperm, and a fertilization process that has been characterized as "intermediate" between Lepidopleurida and all other studied Chitonida [32, 94]. In Lepidopleurida, fertilization occurs by fusion of sperm with a typical metazoan acrosome with the egg, thus transferring not only the chromatin but also the rest of the organelles into the egg cytoplasm, as is the case in most mollusks and metazoans [32]. In Callochiton and all other Chitonida, the sperm digests a minute pore in the egg hull and injects only the chromatin, leaving out all other organelles [32, 94]. This unique mechanism prevents the transmission of male mitochondrial DNA [1, 32]. Reports of dual mitochondrial inheritance are rare (but occur in some bivalve mollusks; 94) and no evidence for such mechanism exists in Lepidopleurida. Nevertheless, the fertilization in Lepidopleurida is known only for Leptochiton asellus plus indirect evidence from two other species [32] and a more general study with broader sampling of Lepidopleurida species would be needed to confirm the generality of these different fertilization processes. Callochiton has been included into Chitonida [23] based on the shared presence 
of slits in valve insertion plates and the typical lateral gill placement and not posterior as in Lepidopleurida [1, 33, 34, 96]. Without Callochiton, the remaining Chitonida could be defined by synapomorphies of asymmetrical sperm mitochondria [30] and the possession of elaborate egg hull projections [33, 34, 97], although egg hulls in Chitonina and Acanthochitonina are of two contrasting types and could have evolved independently.

Lepidopleurida are mostly defined based on plesiomorphic characters such as the presence of unslitted valve insertion plates, a posterior gill arrangement (adanal), simple gamete structures, and special aesthete innervation patterns $[23,96]$. The only defining synapomorphy might be the sensory "Schwabe organ" [26]. From a molecular viewpoint the monophyly of extant Lepidopleurida has only been tested in a single study that included two genera of Lepidopleurida [28] as other analyses did not include non-chiton outgroups and assumed their monophyly (e.g., 28). The recognition of Nierstraszella in its own family Nierstraszellidae Sirenko, 1992 and away from representatives of Leptochitonidae is supported by its morphology, characterized by a fleshy proteinaceous layer that covers the dorsal shell surface [98]. Our analyses found Leptochiton nexus to be more closely related to Hanleyella oldroydi than to Leptochiton rugatus. Previous analyses of the species-rich cosmopolitan genus Leptochiton have not supported it as monophyletic, which has long been suspected given the vague anatomical diagnosis and the lack of defining synapomorphies [99].

In previous molecular phylogenies, the monophyly of Chitonina has been supported by Irisarri et al. [26] but not by Okusu et al. [24] due to the position of Schizochiton incisus, a hypothesis that could not be tested in our study. While the monophyly of the family Chitonidae was well supported, Ischnochitonidae was recovered as non-monophyletic, albeit with low support (Ischnochiton hakodadensis was closer to Chaetopleura than to Tonicina). About half of all living chiton species belong to Chitonina and resolving its phylogeny will require further studies with a broader taxon sampling.

Within Acanthochitonina, Plaxiphora was recovered either as sister to all other Acanthochitonina (partitioned analyses of the combined matrices; $0.99 \mathrm{BPP}$ and $<70 \%$ BP; Fig. 2 and Additional file 4) or as sister to Mopalioidea to the exclusion to Cryptoplacoidea (BI CAT-GTR, $0.68 \mathrm{BPP}$ and ML MtZoa, 42\% BP; Additional file 4). In either case, Plaxiphora lies well outside Mopaliidae, as shown previously by other molecular studies [26, 27]. This is in agreement with aesthete morphology: Plaxiphora shows more similarities to Acanthochitonidae than to Mopaliidae [29]. The large phylogenetic distance between Plaxiphora and Mopalia (Mopaliidae) is noteworthy given their similarities in external morphology, with a broad body outline and girdles covered with corneous hairs (Plaxiphora) or setae (Mopalia and other members of Mopaliidae). If this represents a case of convergence, as hypothesized previously for other chitons [23], the adaptive advantages of this morphology are worth investigating. One of such similarities between Plaxiphora and Mopalia is the presence of a sinus in the posterior valve, long used as a defining character for Mopaliidae [23, 100]. However, our topology implies that the posterior sinus probably evolved multiple times independently in Acanthochitonina, which has been suggested to associate with escalating demands of oxygen in response to increasing body size [26]. Nuttallochiton was found to be closely related to other included Cryptoplacoidea with strong support, in agreement with previous molecular studies [24, 27]. This implies that the current taxonomic placement of Nuttallochiton within Mopaliidae [23] is likewise in need of revision. Our analyses, in agreement with the latest molecular studies, confirm the inclusion of Hemiarthrum in Cryptoplacoidea [26, 27], supported by the presence of spicule tufts in its girdle and abanal gill features [92].

The Mopaliodea grouping of Mopaliidae plus Lepidochitonidae, each as currently defined [26], was strongly supported as in previous studies [26, 27]. The inclusion of members of Tonicella as nested within Mopaliidae (e.g. [25], herein) precludes the alternative association of genera here grouped as Lepidochitonidae Iredale, 1914 within Tonicellidae Simroth, 1894 [23], although we point out that the latter could be a senior synonym of Mopaliidae Dall, 1889 with further study. Meanwhile, Mopaliidae comprises morphologically diverse genera that were formerly placed in other families, united by their mostly North Pacific distribution [25, 77]. In contrast, Nuttallochiton and Plaxiphora, conventionally members of Mopaliidae, occur mostly in the Southern Hemisphere [101, 102]. The geographic restriction of the North Pacific clade thus has few exceptions, such as the North Atlantic Boreochiton ruber (Linnaeus, 1767) and Tonicella marmorea (O. Fabricius, 1780), but these species are either the same or very similar species within these genera of otherwise exclusively North Pacific distribution [103], which suggests a geologically recent invasion of the North Atlantic. The only other exception is Placiphorella, whose deep-water members have a nearly cosmopolitan distribution [104].

\section{A molecular timescale for chiton evolution}

According to paleontological and embryological studies, a Cambrian [105] chiton-like aculiferan ancestor with seven or eight dorsal plates $[8,11]$ gave rise to living chitons (Neoloricata), Solenogastres and Caudofoveata (which underwent a secondary simplification towards 
their current vermiform morphology) and other fossil forms including "paleoloricates" and multiplacophorans $[6,9,106]$. The Cambrian split between extant chitons, solenogasters, and caudofoveates is recovered by our timetrees, regardless of whether Ordovician (Echinochiton; calibration 1a) or Silurian (Acaenoplax; calibration 1b) fossils were used to calibrate this node, and in agreement with previous molecular clock analyses $[6,11]$. Our molecular clock analyses inferred a Carboniferous age for the crown-group Polyplacophora, regardless of whether Early Jurassic Allochiton, Heterochiton, and Ischnochiton marloffsteinensis (calibration 4a) or more recent Late Cretaceous Chiton (calibration 4b) were used as calibrations for the first appearance of Chitonida. The Carboniferous age of the crown-group Polyplacophora agrees not only with previous molecular clock analyses $[6,11]$ but also with the fossil record, where the earliest neoloricates with an articulamentum shell layer extending as sutural laminae (or apophyses) are found in Carboniferous deposits [3, 23]. Note however that this shell layer has been reported in multiplacophorans [107]. The articulamentum shell layer would eventually provide new opportunities of increased complexity in both musculature binding of valves and to the girdle, likely resulting in greater mobility [23]. The Late Carboniferous to Early Permian age estimated for Chitonida (excluding Callochiton) is in line with previous molecular clock analyses $[6,11]$ and some fossils. However, there remains much uncertainty about the interpretation of Paleozoic fossils. Notably, the phylogenetic affinity of the Permian Ochmazochiton comptus Hoare \& Smith, 1984 has been debated, being considered either within (e.g., [23]) or outside (e.g., [6]) the Chitonida crown group, which has implications for the first appearance of Chitonida. Sirenko [23] interpreted the jagged margins of insertion plates as primitive slits that might have functioned, as in extant Chitonida, to allow the innervation of the dorsal tegmentum sensory organs (aesthetes), but these slits show very little resemblance to the slit rays of extant Chitonida.

The origin of crown-group Lepidopleurida was dated in the Triassic. The inferred Jurassic age of the family Leptochitonidae is somewhat younger than the earliest records of fossils identified as Leptochiton in the Late Triassic [20]. This disagreement could indicate problems due to limited taxon sampling, misspecified molecular clock models, or uncertainties in available calibrations. Alternatively, a Jurassic age of Leptochitonidae would imply that older fossils could be currently misclassified within the family and thus in need of a careful re-examination.

Interestingly, the chronology of events described above for the deepest splits within Aculifera and Polyplacophora agree with some previous molecular clock analyses that differed substantially from ours in taxon sampling and methodology: a metazoan-wide molecular dataset with limited chiton representatives calibrated with fossils exclusively outside of Polyplacophora [6] or the same dataset complemented with morphological characters of extant and extinct species into a total-evidence analysis [11]. However, this apparent agreement might also derive in part by the use of relatively broad (conservative) calibrations in our analyses, reflecting the inherent uncertainty associated with Paleozoic aculiferan fossils. Fossil calibrations are often the most crucial aspect in molecular clock analyses and a priori paleontological evaluation of calibrations remains the best strategy to ensure accurate molecular dates [108]. Moreover, the precision of estimated divergence times (HPD intervals) also reflects the uncertainty underlying the fossil record [81] and improving such estimates will necessarily require better knowledge of the molluscan paleontological record.

According to our timetrees, the early divergences within Chitonina occurred in the Jurassic, followed by divergences of most families and subfamilies represented in our timetree during the Cretaceous. This includes members of Chitonidae that represent, together with Lorica (Loricidae), the oldest known fossils for extant taxa within Chitonina [23, 79]. In this case, the Jurassic Allochiton and Heterochiton [76], earlier assigned to Mopaliidae (Acanthochitonina) (e.g., 23) but recently treated more generally as early Chitonida [20], and Ischnochiton marloffsteinensis would represent some of the oldest known members of Chitonida. Awaiting a careful re-evaluation of characters in these fossils (such as the presence of slit rays), our inferred Triassic to Jurassic ages are potentially compatible with their classification within Acanthochitonina (Allochiton, Heterochiton) and Chitonina (Ischnochiton marloffsteinensis) (Fig. 3).

Members of Mopaliidae and part of Lepidochitonidae as currently defined [25, 26], display a mostly North Pacific distribution. Several of its genera have been hypothesized to diversify in the last $16 \mathrm{Ma}$, after the Late Miocene cooling of the North Pacific, possibly mediated by an increase in productivity and environmental heterogeneity $[25,77]$. The fossil record shows a high diversity of chiton species, including members of Mopaliidae, in the Pacific coast by the Late Pliocene, but chitons are strikingly absent from the known Miocene deposits of Western North America [23, 25, 77]. Our molecular clock analyses inferred Cretaceous ages for the common ancestors of both Lepidochitonidae and Mopallidae (92 and 104 Ma, respectively, under our preferred analysis; Fig. 3). These older estimates seem to be in conflict with the 


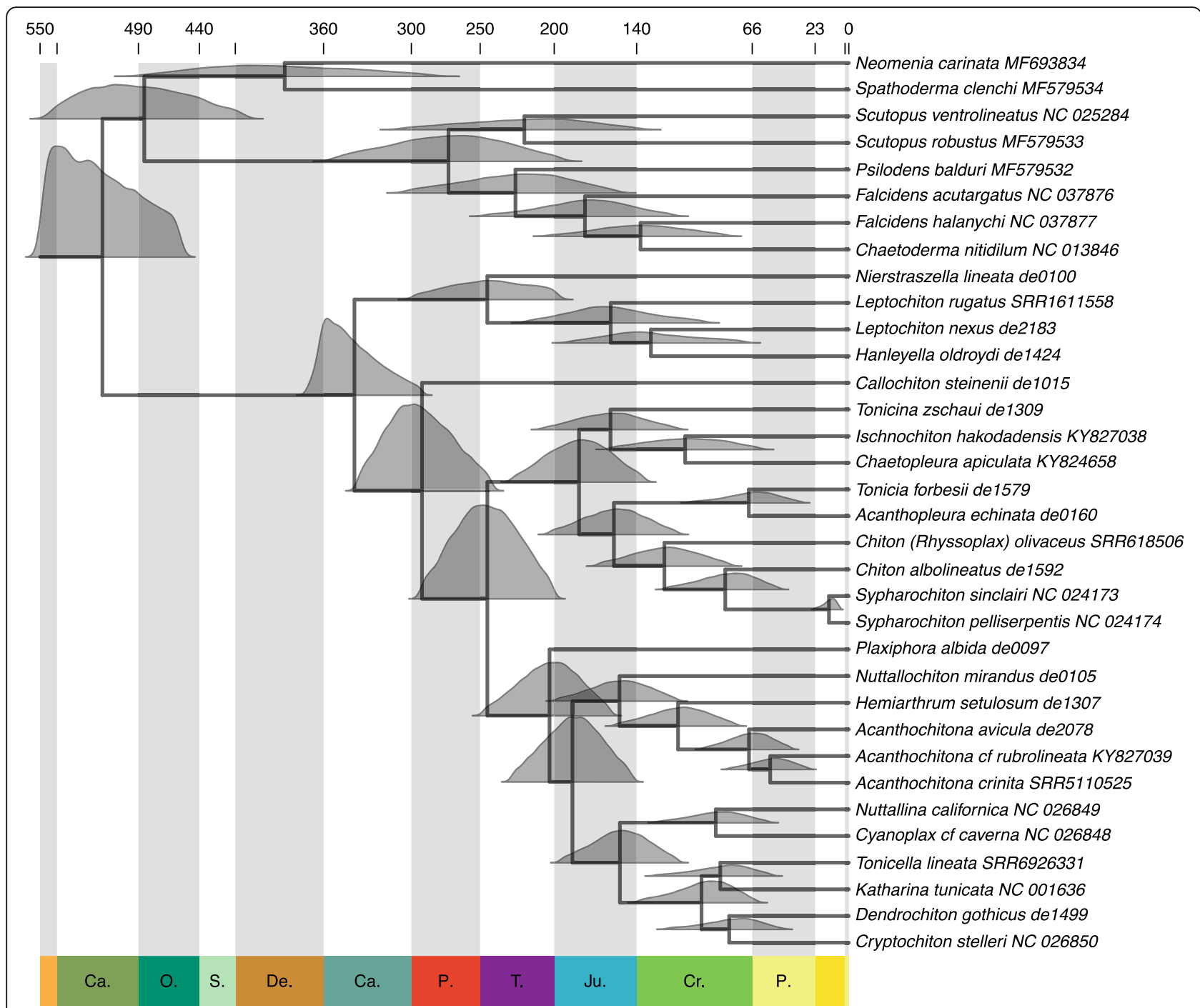

Fig. 3 Time-calibrated phylogeny of Aculifera. Divergence times are inferred with MCMCTree under an uncorrelated relaxed clock and calibration Scheme 1 (fossils 1a-4a) using uniform calibrations. Node ages correspond to posterior means and full posterior distributions are also shown. Scale is in million years ago (Ma) and main geologic periods are highlighted

hypothesized Late Miocene diversification within Mopalia [25], but our taxon sampling and the lack of older fossils does not currently allow testing the deeper diversification within Mopaliidae, Lepidochitonidae, and Mopalioidea as a whole. As a consequence, we call for a more focused study with appropriate taxon sampling and combining molecular clocks and biogeographic reconstructions.

\section{Conclusions}

We demonstrate the suitability of mitogenomes to infer robust molecular phylogenies of living chitons. We find an overall stasis in chiton mitochondrial gene orders, which may be beneficial for phylogenetic reconstruction by limiting the negative effects of rate and compositional heterogeneity among lineages. In addition, the rare genomic reorganizations involving mostly tRNA genes may be seen as molecular synapomorphies with taxonomic value. The inferred phylogenetic tree largely agrees with the latest advances in chiton phylogeny and taxonomy, but also reveal important changes that call for a revision of the higherlevel classification of chitons. Moreover, the proposed phylogenetic hypotheses shed light into the evolution of several morphological characters, identifying new instances of convergence in external morphology. In this sense, our study illustrates the importance of considering independent data sources (e.g., from molecules and morphology) to better understand the origin and evolution of morphological characters and 
assess their phylogenetic and taxonomic utility. The divergences inferred by our molecular clock analsyes largely agreed with previous timetree estimates and the fossil record, but there remains considerable uncertainty associated with available fossil calibrations. In the near future, nuclear phylogenomic and emerging mitogenomic datasets are expected to significantly advance the resolution of the chiton phylogeny.

\section{Supplementary information}

Supplementary information accompanies this paper at https://doi.org/10. 1186/s12862-019-1573-2.

Additional file 1. Taxon sampling, locality and specimen vouches.

Information on taxon sampling, locality and specimen vouchers.

Additional file 2. PCR primers and mitogenome annotation.

Information on universal and species-specific PCR primers and annotation of newly sequenced mitogenomes.

Additional file 3. Model selection, model cross validation, and convergence of Bayesian analyses. Selection of best-fit models and partitions (IQ-TREE), model cross-validation (PhyloBayes), and convergence of Bayesian analyses (PhyloBayes, MrBayes).

Additional file 4. Additional phylogenetic trees. Additional results from partitioned and unpartitioned maximum likelihood and Bayesian analyses.

Additional file 5. Compositional heterogeneity. Results from $x^{2}$-tests (IQ-TREE) and matched-pair tests of symmetry (SymTest) from the protein dataset.

Additional file 6. Time-calibrated trees and correlation coefficients. Time-calibrated trees from all 24 experimental conditions (MCMCTree) and matrix of correlation coefficients among mean posterior ages.

Additional file 7. Inferred divergence times. Inferred mean ages and 95\% highest probability density (HPD) for all 24 experimental conditions (MCMCTree) and reference tree with node IDs.

\section{Abbreviations}

Bl: Bayesian inference; BIC: Bayesian information criterion; BP: Bootstrap proportions; BPP: Bayesian posterior probabilities; HPD: Highest probability density; Ma: Million years ago; ML: Maximum likelihood; rRNA: Ribosomal RNA; t-cauchy: Truncated cauchy; tRNA: Transfer RNA

\section{Acknowledgements}

We thank the following people and institutions for specimens: Tomoyuki Nakano (Nierstraszella lineata), Richard Emlet (Plaxiphora albida 5133), Margaret Amsler and J.B. McClintock from Oregon University (Hemiarthrum setulosum), Susanne Lockhart, the ICEFISH cruise, and cruise leader H.W. Detrich (Nuttallochiton mirandus). We are grateful to Samuel Abalde for laboratory assistance, to Sandra Álvarez-Carretero and Mario dos Reis for help in setting up MCMCTree, and to Jesús Marco and Aída Palacio for providing access to and support with the Altamira supercomputer. We thank two anonymous reviewers for their valuable feedback. We are grateful to Dr. Kathryn Dickson, Chair of the Department of Biological Science at California State University Fullerton in 2010 for supporting II's visit to DJE's Lab. Computations were performed on resources provided by the Spanish Supercomputing Network at the Institute of Physics of Cantabria (IFCA-CSIC) (Altamira), and the Swedish National Infrastructure for Computing (SNIC) at Uppsala Multidisciplinary Center for Advanced Computational Science (UPPMAX) under Project SNIC 2018/8-213.

\section{Authors' contributions}

DJE obtained tissue and genomic DNA samples; II and JEU generated and analysed data in the labs of DJE and RZ; II drafted the manuscript with substantial contributions from the other authors; all authors have read and approved the final manuscript.

\section{Funding}

This work was supported by the Spanish Ministries of Science and Innovation (MICINN; project CGL2010-18216 to RZ) and of Science and Competitiveness (MINECO; project CGL2016-75255-C2-1-P (AEI/FEDER, UE) to RZ) and the U.S. National Science Foundation (NSF-DEB-1355230 to DJE). I was supported by a JAE-predoc PhD fellowship from the Spanish Research Council (CSIC), co-funded by the European Social Fund (ESF), and a postdoctoral Juan de la Cierva-Incorporación postdoctoral fellowship (IJCl-201629566) from MINECO. JEU was supported by fellowships from the MINECO (BES-2011-051469) and the Peter Buck Postdoctoral Fellowship Program from the Smithsonian Institution. The funding bodies played no role in the design of the study and collection, analysis, and interpretation of data, and in writing the manuscript. Open access funding provided by Uppsala University.

\section{Availability of data and materials}

The datasets supporting the conclusions of this article are available as Additional files and in the Figshare repository, https://doi.org/10.6084/m9. figshare.7963712.

Ethics approval and consent to participate

Not applicable.

\section{Consent for publication}

Not applicable.

\section{Competing interests}

Rafael Zardoya is Associate Editor for BMC Evolutionary Biology.

\section{Author details}

${ }^{1}$ Department of Biodiversity and Evolutionary Biology, Museo Nacional de Ciencias Naturales (MNCN-CSIC), c/ José Gutiérrez Abascal 2, 28006 Madrid, Spain. ${ }^{2}$ Department of Organismal Biology (Systematic Biology Program), Evolutionary Biology Centre, Uppsala University, Norbyv. 18C, 75236 Uppsala, Sweden. ${ }^{3}$ Department of Invertebrate Zoology, Smithsonian Institution, National Museum of Natural History, 10th St. \& Constitutional Ave. NW, Washington, DC 20560, USA. ${ }^{4}$ Department of Biological Science, California State University Fullerton, 800 N. State College Blvd, Fullerton, CA 92831-3599, USA.

\section{Received: 20 August 2019 Accepted: 30 December 2019}

\section{References}

1. Eernisse DJ, Reynolds PD. Polyplacophora. In: Harrison FW, Kohn AJ, editors. Microscopic Anatomy of Invertebrates, Volume 5. Mollusca 1. New York: Wiley-Liss; 1994. p. 56-110.

2. Schwabe E. A catalogue of recent and fossil chitons (Mollusca: Polyplacophora) addenda. Novapex. 2005;6:89-105.

3. Puchalski SS, Eernisse DJ, Johnson CC. The effect of sampling bias on the fossil record of chitons (Mollusca, Polyplacophora). Am Malacol Bull. 2008;25: 87-95.

4. Kocot KM, Cannon JT, Todt C, Citarella MR, Kohn AB, Meyer A, et al. Phylogenomics reveals deep molluscan relationships. Nature. 2011;477: 452-6.

5. Smith S, Wilson N, Goetz F, Feehery C, Andrade S, Rouse G, et al. Resolving the evolutionary relationships of molluscs with phylogenomic tools. Nature. 2011:480:364-7.

6. Vinther J, Sperling EA, Briggs DEG, Peterson KJ. A molecular palaeobiological hypothesis for the origin of aplacophoran molluscs and their derivation from chiton-like ancestors. Proc R Soc B. 2012;279:1259-68.

7. Osca D, Irisarri I, Todt C, Grande C, Zardoya R. The complete mitochondrial genome of Scutopus ventrolineatus (Mollusca: Chaetodermomorpha) supports the Aculifera hypothesis. BMC Evol Biol. 2014;14:197.

8. Sigwart JD, Sutton MD. Deep molluscan phylogeny: synthesis of palaeontological and neontological data. Proc R Soc B. 2007;274:2413-9.

9. Sutton MD, Briggs DEG, Siveter DJ, Siveter DJ, Sigwart JD. A Silurian armoured aplacophoran and implications for molluscan phylogeny. Nature. 2012;490:94-7.

10. Sutton MD, Sigwart JD. A chiton without a foot. Palaeontology. 2012;55: 401-11. 
11. Vinther J, Parry L, Briggs DEG, Van Roy P. Ancestral morphology of crowngroup molluscs revealed by a new Ordovician stem aculiferan. Nature. 2017; 542:471-4.

12. Scherholz M, Redl E, Wollesen T, Todt C, Wanninger A. From complex to simple: myogenesis in an aplacophoran mollusk reveals key traits in aculiferan evolution. BMC Evol Biol. 2015;15:201.

13. Salvini-Plawen L, Steiner G. Synapomorphies and plesiomorphies in higher classification of the Mollusca. In: Taylor JD, editor. Origin and Evolutionary Radiation of the Mollusca. 1. Oxford, New York: Oxford University Press; 1996. p. 29-51.

14. Wingstrand K. On the anatomy and relationships of recent Monoplacophora. Galathea Rep. 1985;16:7-94.

15. Giribet G, Okusu A, Lindgren AR, Huff SW, Schrödl M, Nishiguchi M. Evidence for a clade composed of molluscs with serially repeated structures: monoplacophorans are related to chitons. Proc Natl Acad Sci U S A. 2006; 103:7723-8.

16. Stöger I, Sigwart JD, Kano Y, Knebelsberger T, Marshall BA, Schwabe E, et al. The continuing debate on deep molluscan phylogeny: evidence for Serialia (Mollusca, Monoplacophora + Polyplacophora). Biomed Res Int. 2013; 407072.

17. Wägele JW, Letsch $H$, Klussmann-Kolb A, Mayer C, Misof B, Wagele $H$. Phylogenetic support values are not necessarily informative: the case of the Serialia hypothesis (a mollusk phylogeny). Front Zool. 2009;6:12.

18. Vendrasco MJ, Runnegar B. Late Cambrian and Early Ordovician stem group chitons (Mollusca: Polyplacophora) from Utah and Missouri. J Paleontol. 2004;78:675-89.

19. Vendrasco MJ, Wood TE, Runnegar BN. Articulated Palaeozoic fossil with 17 plates greatly expands disparity of early chitons. Nature. 2004;429:288-91.

20. Sirenko Bl. Four new species and one new genus of Jurassic chitons (Mollusca: Polyplacophora: Lepidopleurida) from the middle Russian Sea. Proc Zool Inst RAS. 2013;317:30-44.

21. Dell'Angelo B, Sosso M, Prudenza M, Bonfitto A. Notes on fossil chitons. 5. Polyplacophora from the Pliocene of Western Liguria, Northwest Italy. Riv Ital Paleontol Stratigr. 2013;119:65-107.

22. Fiedel U, Keupp H. Ischnochiton marloffsteinensis n. sp., eine Polyplacophore aus dem fränkischen Lias Paläont Z; 1988. p. 62.

23. Sirenko Bl. New outlook on the system of chitons (Mollusca: Polyplacophora). Venus. 2006;65:27-49.

24. Okusu A, Schwabe E, Eernisse DJ, Giribet G. Towards a phylogeny of chitons (Mollusca, Polyplacophora) based on combined analysis of five molecular loci. Org Divers Evol. 2003;3:281-302.

25. Kelly RP, Eernisse DJ. Reconstructing a radiation: the chiton genus Mopalia in the North Pacific. Invert Syst. 2008;22:17-28.

26. Irisarri I, Eernisse DJ, Zardoya R. Molecular phylogeny of Acanthochitonina (Mollusca: Polyplacophora: Chitonida): three new mitochondrial genomes, rearranged gene orders and systematics. J Nat Hist. 2014;48:1-29.

27. Sigwart JD, Stoeger I, Knebelsberger T, Schwabe E. Chiton phylogeny (Mollusca: Polyplacophora) and the placement of the enigmatic species Choriplax grayi (H. Adams \& Angas). Invert Syst. 2013;27:603-21.

28. Sigwart JD, Schwabe E, Saito H, Samadi S, Giribet G. Evolution in the deep sea: a combined analysis of the earliest diverging living chitons (Mollusca: Polyplacophora: Lepidopleurida). Invert Syst. 2011;24:560-72.

29. Vendrasco MJ, Fernandez CZ, Eernisse DJ, Runnegar B. Aesthete canal morphology in the Mopaliidae (Polyplacophora). Am Malacol Bull. 2008;25 51-69.

30. Buckland-Nicks J. Ultrastructure of sperm and sperm-egg interaction in Aculifera: implications for molluscan phylogeny. Mém Mus Nat Hist Nat Paris. 1995;166:129-53.

31. Sigwart J, Sumner-Rooney L, Schwabe E, HeSZ M, Brennan G, Schrodl M. A new sensory organ in "primitive" molluscs (Polyplacophora: Lepidopleurida), and its context in the nervous system of chitons. Front Zool. 2014;11:7.

32. Buckland-Nicks J. Fertilization biology and the evolution of chitons. Am Malacol Bull. 2008;25:97-111.

33. Eernisse DJ. Lepidochitona Gray, 1821 (Mollusca: Polyplacophora), from the pacific coast of the United States: systematics and reproduction. Santa Cruz: University of California; 1984.

34. Sirenko Bl. Revision of the system of the order Chitonida (Mollusca: Polyplacophora) on the basis of correlation between the type of gills arrangement and the shape of the chorion processes. Ruthenica. 1993;3:93-117.

35. Schwabe E. Illustrated symmary of chiton terminology (Mollusca, Polyplacophora). Spixiana. 2010;33:171-94.
36. MolluscaBase. Chitonoidea Rafinesque, 1815. Accessed through: World Register of Marine Species at: http://www.marinespecies.org/aphia.php?p= taxdetails\&id=385404 on 2019-03-19 [Internet]. 2020.

37. Bernt M, Bleidorn C, Braband A, Dambach J, Donath A, Fritzsch G, et al. A comprehensive analysis of bilaterian mitochondrial genomes and phylogeny. Mol Phylogenet Evol. 2013;69:352-64.

38. Tsaousis AD, Martin DP, Ladoukakis ED, Posada D, Zouros E. Widespread recombination in published animal mtDNA sequences. Mol Biol Evol. 2005; 22:925-33.

39. Boore JL. Animal mitochondrial genomes. Nuc Acids Res. 1999:27:1767-80.

40. Boore JL, Brown WM. Big trees from little genomes: mitochondrial gene order as a phylogenetic tool. Curr Opin Genet Dev. 1998;8:668-74.

41. Brown WM, George MJ, Wilson AC. Rapid evolution of animal mitochondrial DNA. Proc Natl Acad Sci U S A. 1979;76:1967-71.

42. Irisarri I, San Mauro D, Abascal F, Ohler A, Vences M, Zardoya R. The origin of modern frogs (Neobatrachia) was accompanied by acceleration in mitochondrial and nuclear substitution rates. BMC Genomics. 2012;13:626.

43. Irisarri I, Baurain D, Brinkmann H, Delsuc F, Sire J-Y, Kupfer A, et al. Phylotranscriptomic consolidation of the jawed vertebrate timetree. Nat Ecol Evol. 2017;1:1370-8.

44. $\mathrm{Xu} \mathrm{W}$, Jameson $\mathrm{D}$, Tang $\mathrm{B}$, Higgs $\mathrm{P}$. The relationship between the rate of molecular evolution and the rate of genome rearrangement in animal mitochondrial genomes. J Mol Evol. 2006;63:375-92.

45. Mikkelsen NT, Kocot KM, Halanych KM. Mitogenomics reveals phylogenetic relationships of caudofoveate aplacophoran molluscs. Mol Phylogenet Evol. 2018;127:429-36.

46. Uribe JE, Irisarri I, Templado J, Zardoya R. New patellogastropod mitogenomes help counteracting long-branch attraction in the deep phylogeny of gastropod mollusks. Mol Phylogenet Evol. 2019;133:12-23.

47. Guerra D, Bouvet K, Breton S. Mitochondrial gene order evolution in Mollusca: inference of the ancestral state from the mtDNA of Chaetopleura apiculata (Polyplacophora, Chaetopleuridae). Mol Phylogenet Evol. 2018;120:233-9.

48. Veale AJ, Williams L, Tsai P, Thakur V, Lavery S. The complete mitochondrial genomes of two chiton species (Sypharochiton pelliserpentis and Sypharochiton sinclairi) obtained using Illumina next generation sequencing. Mitochondr DNA. 2014:1-2.

49. Sambrook J, Fritsch EF, Maniatis T. Molecular cloning: a laboratory manual. Cold Spring Harbor, New York: Cold Spring Harbor Laboratory Press; 1989.

50. Kornobis E, Cabellos L, Aguilar F, Frías-López C, Rozas J, Marco J, et al. TRUFA: a user-friendly web server for de novo RNA-seq analysis using cluster computing. Evol Bioinform. 2015;11:EBO:S23873.

51. Andrews S. FastQC. High Throughput Sequence QC Report. 2020. https:// www.bioinformatics.babraham.ac.uk/projects/fastqc/.

52. Schmieder R, Edwards R. Quality control and preprocessing of metagenomic datasets. Bioinform. 2011;27:863-4.

53. Grabherr MG, Haas BJ, Yassour M, Levin JZ, Thompson DA, Amit I, et al. Fulllength transcriptome assembly from RNA-Seq data without a reference genome. Nat Biotechnol. 2011;29:644-52.

54. Boore JL, Macey JR, Medina M. Sequencing and comparing whole mitochondrial genomes of animals. Methods Enzymol. 2005;395:311-48.

55. Guo X, Cui Y, Wang S, Xu Y, Sun X, Li R, et al. The complete mitochondrial genome and phylogenetic analysis of Acanthochitona rubrolineatus (Lischke, 1873). Mitochondr DNA Part B. 2019;4:2622-4.

56. Cui Y, Guo X, Wang S, Xu Y, Sun X, Li R, et al. The complete mitochondrial genome and phylogenetic analysis of Ischnochiton hakodadensis (Carpenter, 1893). Mitochondr DNA Part B. 2019;4:2619-21.

57. De Oliveira AL, Wollesen T, Kristof A, Scherholz M, Redl E, Todt C, et al. Comparative transcriptomics enlarges the toolkit of known developmental genes in mollusks. BMC Genomics. 2016;17:905.

58. Halanych KM, Kocot KM. Repurposed transcriptomic data facilitate discovery of innate immunity toll-like receptor (TLR) genes across Lophotrochozoa. Biol Bull. 2014;227:201-9.

59. Riesgo A, Andrade S, Sharma P, Novo M, Perez-Porro A, Vahtera V, et al. Comparative description of ten transcriptomes of newly sequenced invertebrates and efficiency estimation of genomic sampling in non-model taxa. Front Zool. 2012;9:33.

60. Kocot KM, Todt C, Mikkelsen NT, Halanych KM. Phylogenomics of Aplacophora (Mollusca, Aculifera) and a solenogaster without a foot. Proc R Soc B. 2019;286:20190115.

61. Altschul SF, Gish W, Miller W, Myers EW, Lipman DJ. Basic local alignment search tool. J Mol Biol. 1990;215:403-10. 
62. Boore $J$, Brown WM. Complete DNA sequence of the mitochondrial genome of the black chiton, Kathrina tunicata. Genet. 1994;138:423-43.

63. Edgar RC. MUSCLE: multiple sequence alignment with high accuracy and high throughput. Nuc Acids Res. 2004;32:1792-7.

64. Gouy M, Guindon S, Gascuel O. SeaView version 4: a multiplatform graphical user interface for sequence alignment and phylogenetic tree building. Mol Biol Evol. 2010;27:221-4

65. Criscuolo A, Gribaldo S. BMGE (Block Mapping and Gathering with Entropy): a new software for selection of phylogenetic informative regions from multiple sequence alignments. BMC Evol Biol. 2010;10:210.

66. Nguyen L-T, Schmidt HA, von Haeseler A, Minh BQ. IQ-TREE: a fast and effective stochastic algorithm for estimating maximum-likelihood phylogenies. Mol Biol Evol. 2015;32:268-74.

67. Ababneh F, Jermiin LS, Ma C, Robinson J. Matched-pairs tests of homogeneity with applications to homologous nucleotide sequences. Bioinform. 2006;22:1225-31.

68. Le SQ, Gascuel O, Lartillot N. Empirical profile mixture models for phylogenetic reconstruction. Bioinform. 2008;24:2317-23.

69. Lartillot N, Rodrigue N, Stubbs D, Richer J, PhyloBayes MPI. Phylogenetic reconstruction with infinite mixtures of profiles in a parallel environment. Syst Biol. 2013;62:611-5.

70. Rambaut A, Drummond AJ. Tracer v. 1.5. 2020. Available from http://beast. community/tracer.

71. Ronquist F, Teslenko M, van der Mark P, Ayres DL, Darling A, Höhna S, et al. MrBayes 3.2: efficient Bayesian phylogenetic inference and model choice across a large model space. Syst Biol. 2012;61:539-42.

72. Pojeta JJ, Eernisse DJ, Hoare RD, Henderson MD. Echinochiton dufoei: a new spiny Ordovician chiton. J Paleontol. 2003;77:646-54.

73. Sutton MD, Briggs DEG, Siveter DJ, Siveter DJ. An exceptionally preserved vermiform mollusc from the Silurian of England. Nature. 2001;410:461.

74. Benton MJ, Donoghue PCJ, Asher RJ, Friedman M, Near TJ, Vinther J. Constraints on the timescale of animal evolutionary history. Palaeontol Electron. 2015;18.1.1FC:1-106.

75. Laghi GF. Upper Triassic chitons from the Italian Dolomites. Lav Soc Venez Sci Nat. 2005;30:79-84.

76. Fucini A. Polyplacophora del Lias inferiore della Montagna di Casale in Sicilia. Palaeontogr Ital. 1912;18:105-27.

77. Vendrasco MJ, Eernisse DJ, Powell CL II, Fernandez CZ. Polyplacophora (Mollusca) from the San Diego formation: a remarkable assemblage of fossil chitons from the Pliocene of southern California. Nat Hist Mus Los Ang County Contrib Sci. 2012;520:15-72

78. Itoigawa J, Nishimoto H. Miocene Polyplacophora assemblage from the Mizunami group, Central Japan (first report). Bull Mizunami Fossil Mus. 1975;2

79. Smith AG, Sohl NF, Yochelson EL. New upper cretaceous Amphineura (Mollusca) description of chitons from the Gulf coastal plain and Puerto Rico. U.S. Washington: Geological Survey; 1968

80. Yang Z. PAML 4: phylogenetic analysis by maximum likelihood. Mol Biol Evol. 2007;24:1586-91.

81. Dos Reis M, Thawornwattana Y, Angelis K, Telford Maximilian J, Donoghue Philip CJ, Yang Z. Uncertainty in the timing of origin of animals and the limits of precision in molecular timescales. Curr Biol. 2015;25:2939-50.

82. Thorne $\mathrm{J}$, Kishino $\mathrm{H}$, Painter IS. Estimating the rate of evolution of the rate of molecular evolution. Mol Biol Evol. 1998;15:1647-57.

83. Yang Z. Maximum likelihood phylogenetic estimation from DNA sequences with variable rates over sites: approximate methods. J Mol Evol. 1994;39:306-14

84. Macey JR, Larson A, Ananjeva NB, Papenfuss TJ. Replication slippage may cause parallel evolution in the secondary structures of mitochondrial transfer RNAs. Mol Biol Evol. 1997;14:30-9.

85. Boore JL. The duplication/ random loss model for gene rearrangement exemplified by mitochondrial genomes of deuterostome animals. In: Sankoff D, Nadeau JH, editors. Comparative Genomics. Dordrecht: Kluwer Academic Publisher; 2000. p. 133-47.

86. San Mauro D, Gower DJ, Zardoya R, Wilkinson M. A hotspot of gene order rearrangement by tandem duplication and random loss in the vertebrate mitochondrial genome. Mol Biol Evol. 2006;23:227-34.

87. Medina M, Lal S, VallËs Y, Takaoka TL, Dayrat BA, Boore JL, et al. Crawling through time: transition of snails to slugs dating back to the Paleozoic, based on mitochondrial phylogenomics. Mar Genomics. 2011:4:51-9.

88. Grande C, Templado J, Cervera JL, Zardoya R. The complete mitochondrial genome of the nudibranch Roboastra europaea (Mollusca: Gastropoda) supports the monophyly of opistobranchs. Mol Biol Evol. 2002;19:1672-85.
89. Irisarri I, San Mauro D, Green DM, Zardoya R. The complete mitochondrial genome of the relict frog Leiopelma archeyi: insights into the root of the frog tree of life. Mitochondr DNA. 2010;21:173-82.

90. Dowton $\mathrm{M}$, Campbell NJH. Intramitochondrial recombination - is it why some mitochondrial genes sleep around? Trends Ecol Evol. 2001;16:269-71.

91. Irisarri I, Meyer A. The identification of the closest living relative(s) of tetrapods: phylogenomic lessons for resolving short ancient internodes. Syst Biol. 2016;65:1057-75.

92. Sirenko Bl. The importance of the development of articulamentum for taxonomy of chitons (Mollusca, Polyplacophora). Ruthenica. 1997;7:1-24.

93. Wilson NG, Rouse GW, Giribet G. Assessing the molluscan hypothesis Serialia (Monoplacophora + Polyplacophora) using novel molecular data. Mol Phylogenet Evol. 2010;54:187-93.

94. Buckland-Nicks J, Hodgson AN. Fertilization in Callochiton castaneus (Mollusca). Biol Bull. 2000;199:59-67.

95. Breton S, Beaupré HD, Stewart DT, Hoeh WR, Blier PU. The unusual system of doubly uniparental inheritance of mtDNA: isn't one enough? Trends Genet. 2007;23:465-74

96. Sigwart JD. Gross anatomy and positional homology of gills, gonopores, and nephridiopores in "basal" living chitons (Polyplacophora: Lepidopleurina). Am Malacol Bull. 2008;25:43-9.

97. Risbec J. Études anatomiques sur les amphineures de la Nouvelle-Calédonie. J Soc Oceanistes. 1964;2:129-90.

98. Sirenko BI. Taiwanese deep-water chitons (Mollusca: Polyplacophora) and survey of chiton fauna of Taiwan. Zootaxa. 2018;4422:301-44.

99. Kaas P, Van Belle RA. Monograph of living chitons. Volume 1. Order Neoloricata: Lepidopleurina. Brill, E. J: Leiden; 1985. p. 240.

100. Van Belle RA. The systematic classification of the chitons (Mollusca: Polyplacophora). Inf Soc Belge Malacol. 1983;13:49-59.

101. Kaas P, Van Belle RA. Monograph of living chitons. Volume 3. Suborder Ischnochitonina. Ischnochitonidae: Chaetopleurinae and Ischnochitoninae (pars). Additions to Vols. 1 and 2. Brill, E. J: Leiden; 1987. p. 302.

102. Kaas P, Van Belle RA. Monograph of living chitons. Volume 5. Suborder Ischnochitonina: Ischnochitonidae: Ischnochitonina (concluded). Callistoplacidae: Mopaliidae. Additions to Vols. 1-4. Brill, E. J: Leiden; 1994. p. 402.

103. Kaas P, Van Belle RA. Monograph of living chitons. Volume 2. Suborder Ischnochitonina. Ischnochitonidae: Schizoplacinae, Callochitoninae and Lepidochitoninae. Brill, E. J: Leiden; 1985. p. 198.

104. Schwabe E. A summary of reports of abyssal and hadal Monoplacophora and Polyplacophora (Mollusca). Zootaxa. 2008;1866:205-22.

105. Pojeta JJ, Vendrasco MJ, Darrough G. Upper Cambrian chitons (Mollusca, polyplacophora) from Missouri. USA Bull Am Paleontol. 2010;379:1-88.

106. Scherholz M, Redl E, Wollesen T, Todt C, Wanninger A. Aplacophoran mollusks evolved from ancestors with polyplacophoran-like features. Curr Biol. 2013;23:2130-4

107. Puchalski SS, Johnson CC, Kauffman EG, Eernisse DJ. A new genus and two new species of multiplacophorans (Mollusca, Polyplacophora, Neoloricata), Mississippian (Chesterian). Indiana J Paleontol. 2009:83:422-30.

108. Parham JF, Donoghue PCJ, Bell CJ, Calway TD, Head JJ, Holroyd PA, et al. Best practices for justifying fossil calibrations. Syst Biol. 2012;61:346-59.

\section{Publisher's Note}

Springer Nature remains neutral with regard to jurisdictional claims in published maps and institutional affiliations.

Ready to submit your research? Choose BMC and benefit from:

- fast, convenient online submission

- thorough peer review by experienced researchers in your field

- rapid publication on acceptance

- support for research data, including large and complex data types

- gold Open Access which fosters wider collaboration and increased citations

- maximum visibility for your research: over $100 \mathrm{M}$ website views per year

At BMC, research is always in progress.

Learn more biomedcentral.com/submission 